\title{
HOME AND AWAY: A CASE STUDY ANALYSIS OF A LEARNING AND TEACHING PROGRAMME SUPPORTING THE DEVELOPMENT OF A 'TRANSFORMATIVE' PARTNERSHIP WITH A PRIVATE HEI IN SRI LANKA
}

Hazel Messenger, Digby Warren and Wendy Bloisi

\begin{abstract}
Transnational arrangements between different types of higher education institutions provide an interesting example of partnership working, being business arrangements with learning as a core organising principle. Successful partnerships both learn and work together and can become mutually transformative, sources of growth for the individuals and institutions involved. Individual projects early in the lifecycle of a
\end{abstract}

University Partnerships for Academic Programs and Professional Development Innovations in Higher Education Teaching and Learning, Volume 7, 141-157 Copyright (C) 2016 by Emerald Group Publishing Limited All rights of reproduction in any form reserved ISSN: 2055-3641/doi:10.1108/S2055-364120160000007018 
partnership can support this development, enabling both organisations to take responsibility for relationship building and the demonstration of trust. This approach has the advantage that it takes the focus away from the home/away dichotomy often apparent in discussions of transnational partnership working and instead attention turns to the development of a new hybrid organisation, a 'third space' characterised by reciprocity, commitment, effective communication, competence and trust.

This chapter provides a case study analysis of a learning and teaching programme which provided the opportunity for a partnership between a London-based university and a private provider in Sri Lanka to have transformational potential. It uses multiple sources of data to identify practical characteristics associated with developing a culture of transformative partnership working which includes the experiences of the 'boundary spanner' responsible for its development and leadership.

Keywords: Partnerships; transformative; university; learning; teaching

\section{INTRODUCTION}

Transnational arrangements between different types of higher education institutions provide an interesting example of partnership working, being a business arrangement with learning as a core organising principle. In a recent document from the Higher Education Academy relating to creating partnerships in a learning and teaching context (HEA, 2014a, p. 2), partnership is understood as; 'a relationship in which all involved are actively engaged in and stand to gain from the process of learning and working together to foster engaged student learning and engaging learning and teaching enhancement'. Partnerships represent a 'wicked' issue (Rittel \& Webber, 1973; Trowler, 2012) giving institutions complex issues to resolve (Wagstaff, 2013), but can become mutually transformative, sources of growth for the individuals and institutions involved (Sutton, 2010).

Sutton (2010) describes partnership activity in transnational education (TNE) as operating on a relational continuum from transactional to transformational. She suggests that a transactional partnership is a business 
relationship, mainly concerned with the product of the relationship, with little impact beyond financial benefit being experienced by the home institution. By contrast, a transformational partnership has the potential to have a wide and long-lasting influence on both institutions, going far beyond what was originally planned. She suggests that transformational partnerships are characterised by being more relationship-orientated, have a long-term expansive perspective and acknowledge that development will involve individual and organisational change, 'expanding the capacity for each institution for educating its students, conducting research and serving communities' (Sutton, 2010, p. 62).

Despite the high institutional risks involved, Wagstaff (2013, p. 8) considers that little is known about what contributes to the successes or failures of TNE partnerships and suggests that organisations should be more proactive in learning from them, including reflecting on changes resulting from being in partnership and how 'individual partnerships are contributing to its own evolving ecology'. Williams (2010) suggests that ethnographic and case study approaches could help with identifying the factors that contribute to the success or failure of partnerships. These types of studies can also include the experiences of the 'boundary spanners' (Williams, 2010, p. 7) who are responsible for their development (Whitchurch, 2008; Williams, 2010, 2012). Citing Kanter (1996), Williams (2010, p. 30) proposes that these individuals have a value-base which encourage 'personal relationships, building trust, communication, negotiation and managing without power' and are also capable of coping with ambiguity and personal stress.

This chapter provides an evaluation of a learning and teaching development programme which contributed positively to the transformative potential of a TNE partnership between higher education institutions in the United Kingdom and Sri Lanka. Using data collected in situ during the programme as well as the reflective account of the coordinator, it proposes that this 'partnership within a partnership' involving partners-asstudents provided what Bhabha termed a 'third space' (Rutherford, 1990, p. 211). In this context the colonial authority of 'home' and 'away' was replaced by a hybrid space and a heightened opportunity for an 'expanded form of learning and the creation of new knowledge' (Gutiérrez, 2008, p. 152). By including reflections from the 'boundary spanner' responsible for the development and implementation of the programme, evidence is also included which may be useful for the professional development of colleagues working in TNE partnerships, an area that Hoare (2013) comments is lacking. 


\title{
TRANSNATIONAL PARTNERSHIPS IN HIGHER EDUCATION
}

TNE provision is defined by $\operatorname{GATE}(2000$, p. 1$)$ as:

\begin{abstract}
Any teaching or learning activity in which the students are in a different country (the host country) to that in which the institution providing the education is based (the home country). This situation requires that national boundaries be crossed by information about the education and by staff and/or education materials (whether the information and the education, and the materials travel by mail, computer network, radio or television broadcast or other means)
\end{abstract}

This rapidly developing phenomenon involves universities internationally working in partnership with overseas education providers (Bohm et al., 2004; British Council, 2013; HEA, 2014b; Montgomery, 2014). Partnership working is common in many sectors, with success at progressing beyond the contractual stage being underpinned by generic relational principles including developing clarity, trust, commitment and organisational learning (Wildridge, Childs, Cawthra, \& Madget, 2004). Healey, Flint, and Harrington (2014) in writing about partnerships in learning and teaching in higher education, indicate that success is based on learning in partnership as well as working in partnership (emphasis in original). It follows therefore, that to develop effective and potentially transformative partnerships, the working relationship needs to incorporate a learning relationship. There is widespread acknowledgement that partnerships in education are highly contextual with their own 'learning culture' (James \& Biesta, 2007, p. 21), influenced by many factors including 'the experiences and expertise of the partners involved, the culture and history of the setting for partnership and the wider social and political context of higher education' (Healey et al., 2014, p. 14). 'Culture' also refers to a cultural theory of learning, which assumes that learning 'is something that happens in and through social practices' (James \& Biesta, 2007, p. 21). These definitions help to identify the factors that might contribute to a culture which has a focus on developing the partnership from a business transaction to something with wider impact. Appreciating the significance of context therefore helps to challenge the polarities often found in discussions relating to TNE, something that Djerasimovic (2014) suggests helps to overcome issues relating to cultural or ideological imperialism. 


\section{PARTNERSHIP DEVELOPMENT IN TRANSNATIONAL EDUCATION}

In their work on transnational partnerships between Australian universities and institutions in the Far East, Heffernan and Poole (2005) suggest that although a partnership may originally be set up as a business transaction, paying attention to the process of developing good relationships from the outset is fundamentally important for high-quality outcomes. In the United Kingdom the Quality Assurance Agency for Higher Education (QAA) demand a focus on the 'ends rather than the means' (QAA, 2012, p. 17), but as Keay, May, and O’ Mahony (2014, p. 265) point out:

working in partnership in TNE contexts goes beyond what can be recorded through a pre-defined partnership agreement ... crucial attention needs to be paid to the process, that is, the way in which partners interact and engage collaboratively over time in order to achieve the best possible outcomes for students.

A number of authors from different sectors consider that partnership development should be seen as a relational and practical lifecycle; for example by Dwyer, Schurr, and Oh (1987) and Child and Faulkner (1998) (for business-to-business partnerships) and Hardy, Hudson, and Waddington (2000) and Gray (1989) (for public sector partnerships). Healey et al. (2014) emphasise the significance of learning relationships and learning communities (emphasis in original) to the development of partnerships in educational contexts, suggesting that a culture of partnership is characterised by a number of critical relational factors including shared vision and values, effective communication, developing trust and personal commitment. Similarly research into successful international business partnerships has identified that communication, trust and commitment are essential influencing features (Ahmed, Patterson, \& Styles, 1999), with the development of trust being the most important of these (Dowell, Heffernan, \& Morrison, 2013). Sutton and Obst (2011) echo this by explaining how transnational partnerships need to focus on the partnership relationship itself and the relationships between the individuals involved as much as on the product of the relationship. They suggest that partnerships require care and nurturing, with patience, flexibility, a focus on relationship building, trust and rapport all essential factors that help to move them forward. However, MacFarlane (2009) identifies that the development of trust in relationships has received less attention in educational literature 
compared to that in business and psychology, and emphasises that this particularly relates to practical and operational factors.

Heffernan (2004), Heffernan and Poole $(2004,2005)$ and Dowell et al. (2013) suggest that it is helpful to see the relational process that characterises transnational partnership development occurring within a five-stage lifecycle. These five stages progress as follows; firstly there is awareness or pre-relationship stage, which is followed by an exploratory, early interaction stage then an expansive, relationship growth stage. Once the partners have established mutual trust and respect and have identified areas of mutual benefit and growth, the lifecycle proceeds to a mature committed stage, finally ending when there is dissolution. This approach, with the partnership seen as an ongoing relational exchange, is based on the relationship marketing model of Dwyer et al. (1987). It has the advantage that it enables identification of ways in which transnational partnership activity may be encouraged to move beyond the initial business transaction, and anticipates that 'establishing, maintaining and developing successful relational exchanges' (Morgan \& Hunt, 1994, p. 20) through effective communication, trust and commitment are significant at all stages. This takes the focus away from a colonialist home/away dichotomy and towards the creation of a reciprocal relationship of mutual benefit where both partners take responsibility for relationship building and exploring possibilities for growth. In a learning and teaching context this would be seen as developing a sense of community between those involved (Healey et al., 2014, p. 28) forming a 'partnership learning community' which 'facilitates deep connections ... leading to enhanced learning and motivation for all community members'.

Heffernan and Poole (2005) consider that the five stages of the lifecycle mark major transitions in how the partners relate to and have regard to each other. Developing a sense of community in the lifecycle of the partnership should not anticipate a smooth, unidirectional path as each of the stages will be influenced by the past and influence the future. Heffernan (2004) suggests that the early interaction stage of a partnership (Dwyer et al., 1987) may be quite fragile because the partners do not know each other well. Heffernan and Poole (2005) consider that it is this stage that is the most significant in partnership development, as it is when impressions and expectations are formed, boundaries established and the possibilities for growth explored. To progress to the next stage there needs to be a high degree of mutual learning, with a high level of interaction and engagement increasing mutual knowledge and reducing uncertainty (Heffernan, 2004). In this way trust is demonstrated and developed with demonstrations of 
rapport, confidence and goodwill showing a commitment to the partnership working. Specific projects can facilitate this process, especially if they are introduced with the anticipation that there will be more projects as time progresses. This is a multi-layered process involving the organisational and individual changes that Sutton (2010) suggests contribute to the development of a transformative partnership.

The remainder of this chapter provides a case study analysis of how a learning and teaching development programme contributed to the transformative potential of a partnership between a UK university and a private higher education institution (HEI) in Sri Lanka. It reviews the programme and reports on the experiences of the development team, indicating the potential for the programme to have a wider impact than what was originally conceived.

\section{CONTEXT}

Sri Lanka has been identified as a region in need of investment to support the development of quality higher education provision (British Council, 2013; The Economist Intelligence Unit, 2013; World Bank, 2009), as statefunded universities are currently only able to provide for $16 \%$ of those eligible to take up places. With a publicly intended aim for Sri Lanka to be an international hub of excellence for higher education by 2020 (Ministry of Higher Education, Sri Lanka, 2012) the Sri Lankan government is therefore encouraging partnerships between non-state (private) HEIs and overseas universities in order to help with this shortfall. Acknowledging the traditional reliance on a transmission style of teaching, they have also stated that they wish to encourage more active learning 'to produce students who think broad and can have open discussions and learning' (Ministry of Higher Education, Sri Lanka, 2012, p. 23).

The partnership arrangement discussed here is between a London-based university and a private educational organisation in Sri Lanka. The university wanted to expand the number of students enroled on its courses and had been actively seeking a partner in a stable south Asian country. This partnership would provide a source of offshore income for the university from the fees being paid and also publicise the university in Sri Lanka. Sri Lanka had been stable since the civil war ended in 2009 and a 'due diligence' investigation (UKHE, 2012, p. 42) had shown that the organisation had a reliable profile which indicated that it would be able to deliver the 
financial aspects of the relationship. The partner also had extensive experience of delivering high-quality pre-degree and professional qualifications, which gave confidence in their ability to deliver the courses to meet the appropriate quality standards. The QAA anticipates that students in the home or partner institution will have equivalent experiences which means that although partnerships may start as a business transaction it is necessary to develop effective collaborative arrangements in order to provide a quality experience for the students (QAA, 2012).

The arrangement started in 2014 when the partner was validated to deliver undergraduate courses in two subject areas, computing and business and postgraduate provision through an executive MBA at its campuses in Colombo and Kandy. Partnership working had been a feature for many years in all of the faculties within the university, with business and law having 15 partners offering a total of 48 courses involving over 1,000 students. Since 2013 these had been brought together and managed by an academic Partnerships Manager with responsibility for monitoring their quality and financial contribution.

The conditions of the validation included the requirement for the university's Centre for the Enhancement of Learning and Teaching (CELT) to provide staff development in teaching and learning in higher education for the staff involved in the business programmes. This requirement resulted in two programmes, both developed in collaboration with CELT and delivered in Sri Lanka by the UK course leader for the MBA (herself an experienced academic developer) with support from the faculty's Partnerships Manager. The first undergraduate-focused programme was delivered over five days at the Colombo campus. The second two-day programme concentrated on postgraduate provision and the new MBA in particular. This was delivered in both Colombo and Kandy in order that members of the staff team who worked in the business sector and taught part-time could attend. Details of both programmes were agreed in advance with the CEO of the Sri Lankan organisation who indicated that he and his senior team would be actively participating.

\section{METHODOLOGY}

Healey et al. (2014, p. 29) explain how it is very difficult to 'see' partnership as a process when it is committed to paper indicating that it is essentially experiential'. This chapter aims to reveal some of the processes involved in 
the development of a partnership by presenting a case study analysis of the implementation of the learning and teaching programmes, with a view to identifying how they might contribute to the potential for the partnership to develop from a business transaction to something more transformative. A case study approach is appropriate for building understanding around a particular issue (Merriam, 1998) with Yin (2009) emphasising the need to take into account context. This is particularly relevant to educational environments (Chickering \& Reisser, 1993) therefore the possibilities for generalising from the case to other contexts needs to be considered. Hodkinson and Hodkinson (2001, p. 11) consider that they prefer not to think about generalisations because of the statistical connotations of the term, instead preferring to propose that findings may be transposed elsewhere if they 'ring true' to the reader.

A case study approach anticipates using multiple sources of data and here these include prepared resources, participants' responses to activities, photographs, formal and informal feedback and the reflective records of the course coordinator. The analysis also includes a narrative account of partnership working in action, providing a 'rare tale' from a 'cross border traveller' (Trahar, 2013, p. 302).

\section{A PARTNERSHIP WITHIN A PARTNERSHIP: AN ANALYSIS OF THE TRANSFORMATIVE POTENTIAL OF A LEARNING AND TEACHING PROGRAMME WITH A PARTNER ORGANISATION IN SRI LANKA}

Sutton (2010, p. 62) emphasises that transformative partnership working understands the reciprocal nature of the relationship and the capability for 'expanding the capacity for each institution for educating its students, conducting research and serving communities'. She suggests that the transformative potential of partnerships can be enhanced through specific projects which enhance mutual learning. Although the learning and teaching development programme appeared to be focused 'away' into the Sri Lankan organisation, its transformative impact was felt in the United Kingdom first as it would reach into the 'home' organisation before it would reach out into the partner. The collaborative development of the programme involved a new partnership between the faculty and CELT which has resulted in involvement in other initiatives within the university. Had 
CELT been able to take sole responsibility for the development programmes the relationships developed would have been quite different.

Prior to the start of the programme each organisation had established a view of the mutual benefit of the partnership and of each other's integrity and competence. Requiring development in learning and teaching could have been perceived as the university lacking trust in its new business partner. However the CEO of the organisation regarded the outcome positively, indicating that he felt that it gave his staff team an excellent opportunity and provided the organisation with a competitive advantage compared to other private HEIs in Sri Lanka. Communication with him during the development of both programmes regarding their style and content helped to communicate the university's commitment to the events, as did the involvement of coordinators who both had high levels of experience and expertise in partnership working and learning and teaching development.

The planned programmes consisted of a blend of formal and informal presentations, group activities, discussions and collaborative feedback. The aim was to encourage a high degree of interaction and engagement between the participants as well as between the organisers and their Sri Lankan colleagues in order to maximise the learning that could occur through this unique opportunity. At the end of each day the rooms where the programmes took place had transformed into working environments where the collaborative work of learning was apparent on flipcharts and sticky notes. Permission had been given to use a camera and the resulting images and their use in further presentations in the United Kingdom and overseas have been a key factor in contributing to the wider reach of the programmes. Photographs of the participants engaged in collaboration and feedback provided a permanent record of the development of inclusive active learning communities where collaboration and sharing knowledge were the norm. This was important as the participants had different backgrounds, different levels within the organisations involved and different types of relationships with each other. Introducing photographs into the pre-prepared formal presentations also provided a humanising element into resources that could have appeared sterile and distant. They also provided amusement, especially around the issue of 'who ate all the sweets'. This collaborative style of working and using photographs as a record has been adopted since by one of the senior members of the Sri Lankan staff team in his work on technologyenhanced learning with colleagues at a local university.

Each programme spanned several days and it was important to receive immediate feedback in order to inform subsequent activities. Feedback on 
the first day of the undergraduate programme gave confidence in the approach being adopted. Participants documented their thoughts regarding professional practice; 'Learnt (sic) different perspectives of others in the lecturing field', and awareness of the coordinators modelling an active style of teaching; 'Today's session initiated an opening to practically experiencing different teaching styles and ways of keeping the students engaged with what is being done'. Similarly, responses to the postgraduate programme identified that the programme was creating the right sort of vibe; 'Interesting, interactive, most useful and appreciated. Much thanks!' and it was possible to note that a hybrid space for mutual learning was emerging; 'It's good experience sharing knowledge with someone from a different context'.

With participants having a wide variety of backgrounds and representing all levels of the Sri Lankan organisation, it was important for the coordinators to recognise the significance of hierarchies and other factors, like gender. Although in the United Kingdom it may have been possible to 'mix things up', in this unfamiliar environment this was not appropriate. An early decision was made to allow groups to form themselves, which meant, for example, that the senior management team worked together. Senior management commented that although they met frequently to discuss business issues, they rarely had the opportunity to discuss learning and teaching. They signalled their personal and organisational commitment to the programmes by remaining involved throughout and indicated the practical value they found in particular concepts, like the work of Chickering and Gamson (1987) and Hounsell, McCune, Hounsell, and Litjens (2008) which could be clearly situated in their own context.

Showing care and respect for the needs of the other is an important part of developing trust in partnership development. The Sri Lankan organisation provided refreshments for everyone during each day which provided informal opportunities for talking and finding out more about each other. Being comfortable and confident in formal and informal settings is an important part of the role of those working in transnational contexts as is having a genuine and ongoing interest about local culture, history, families and hobbies. These informal sessions did not just contribute to the development of relationships between UK and Sri Lankan colleagues, but also to relationships between those employed by the Sri Lankan organisation itself. Although the Sri Lankan team worked for the same organisation, because they worked in different locations and with different contractual arrangements, they did not have many opportunities to get to develop the types of close relationships which help to develop trust. The learning and teaching programme helped individuals to get to know each other, providing the 
chance for the development of 'active trust' (Giddens, 1991, p. 136) between colleagues separated by time and space. This type of 'professional trust' (Hargreaves, 2002, p. 395) is essential for professional effectiveness especially in partnership arrangements involving individuals separated by distance, national boundaries, and status.

By the time the second, postgraduate programme began, each organisation could predict its success based upon the commitment and responsibility already demonstrated throughout the first programme. There was practical demonstration of the values that Healey et al. (2014) suggest should be brought to working in partnership and new ways of working and learning together were beginning to show. By the end of the first programme the type of language being used to talk about learning and teaching had changed; 'Don't just give the task and expect good work from them ... be aware of the feedback cycle' and 'Some students like coursework because they can complete them leisurely with deep learning' and the influence of this was being seen in the collaborative development of the new degree courses.

Although the programmes were dealing with a serious topic, the way in which they had been constructed had allowed all the participants from both partners to relax and get to know each other. There was practical demonstration of being on the same wavelength in what they were aiming to achieve. As time progressed the daily feedback became more natural and in the formal programme evaluation the participants commented that the style adopted was 'interactive', 'interesting' and 'friendly' with comments about the university's coordinators including 'their experience evident from the way they spoke and acted'. That the participants had enjoyed the opportunity to develop and share their ideas was apparent as comments like 'awesome', 'fantastic', 'wonderful' and 'productive' appeared more than once in the feedback sheets. However, one of the participants commented that although they had really enjoyed the opportunities for interaction and debate, their students would be expecting the didactic style that they were accustomed to, which was somewhat deflating.

\section{A NARRATIVE ACCOUNT OF PARTNERSHIP WORKING IN ACTION BY THE DEVELOPMENT PROGRAMME COORDINATOR}

Although the development programme was a requirement of the university and had involved a lot of preparation, including rearranging university 
responsibilities, not all colleagues had seen this programme in a positive light, regarding it as a bit of a holiday. What they might not have realised was the significant sense of responsibility involved in working on the university's behalf in an unfamiliar environment and the personal demands in making it look easy and seamless. However, the first visit to the organisation for the validation had been characterised by goodwill and good humour and had included tours of each campus, formal and informal meetings with the staff and a celebratory dinner with the senior management team. All of this contributed to getting a 'feel' for the organisation and for what it would be like to work together.

Williams (2010) comments on the importance of networks in managing effective collaborations and colleagues around the country had been generous in providing specialist resources and advice during the preparation of the learning and teaching programme. By the time the flight took off to Colombo, a full five-day programme including presentations, activities, handouts and certificates had been prepared, the content had been agreed with the partner's CEO, day-to-day responsibilities were as up-to-date as possible and arrangements had been made for the family's pets. The fact that there had been time to pack clothes in the suitcase alongside flipcharts, sticky notes, felt tips, packs of sweets and delegate packs was an added bonus.

Williams (2010) and Sutton (2010) identify that working in a boundary spanning role involves having an entrepreneurial spirit and an eye for creating new opportunities. Having a dual identity as a teaching academic and educational developer/researcher plus a genuine interest in the human experience of being with another' (Wagstaff, 2013, p. 12) provided the background to wanting to learn more from the implementation of the development programme. Being on the periphery of the organisation was advantageous as it gave the opportunity for initiative and creativity. Although the university did not seem too concerned in how the programme fared, by the end of the year it would be the subject of an international conference presentation, a book chapter and a workshop for other partnership workers funded by an academic development body.

The development programme provided a space for knowledge exchange and learning and the opportunity to work collaboratively with experienced colleagues who had revealed themselves as deeply committed and fun to work with. The second day of the undergraduate programme happened to be April 1, and the fact that one of the senior managers was taken in by a spoof 'Mini Cooper T' introduced in the presentation just before the midmorning break continues to be a source of great delight to everyone who was present. These colleagues are now co-professionals and friends who 
just happen to be on the other side of the world. Although information technology has shrunk the distance between the United Kingdom and Sri Lanka they could still be a million miles away if they were not on the same wavelength. Far from being a 'jolly', the programme represented a type of pilgrimage which enabled revisiting and reinforcing the values associated with learning and working relationships in higher education.

\section{CONCLUSIONS}

To summarise, the key factors that influenced the transformative potential of the learning and teaching programmes were the value in it seen by the management of the partner organisation and the representatives of the university and its capability for demonstrating and reinforcing the values of partnership (Healey et al., 2014). These in turn were influenced by the stage in development of the partnership, the genuine care and respect towards each other of the key organisers and recognition of the importance of relationship building between all those involved. Collectively these might be described as constituting a culture for transformative partnership working.

Having the concept of 'partnership' at the centre of all work transforms individuals and organisations and the ways in which they work with others. Organisational boundaries become fluid and the programme in Sri Lanka had been neither 'home' nor 'away' but a physical, temporal and relational third space (Bhabha in Rutherford, 1990) where the requirements of the validation were translated into practical outcomes which transcended the original purpose. It provided the catalyst for a new co-created culture of partnership learning and working together. This transitional and galvanising space is now helping to create a new hybrid organisation based on relationships rather than structures and processes.

\section{REFERENCES}

Ahmed, F., Patterson, P., \& Styles, C. (1999). The determinants of successful relationships in international business. Australasian Marketing Journal, 7(1), 5-21.

Bohm, A., Follari, M., Hewett, A., Jones, J., Kemp, N., Meares, D., ... Van Cauter, K. (2004). Vision 2020. Forecasting international student mobility: A UK perspective. London: British Council.

British Council. (2013). The shape of things to come: The evolution of transnational education: Data, definitions, opportunities and impacts analysis. Retrieved from https:// 
ihe.britishcouncil.org/sites/default/files/import-content/the_shape_of_things_to_come_ 2.pdf

Chickering, A. W., \& Gamson, Z. F. (1987). Seven principles for good practice in undergraduate education. American Association of Higher Education Bulletin, 39(7), 3-7. Retrieved from http://www.aahea.org/articles/sevenprinciples1987.htm

Chickering, A. W., \& Reisser, L. (1993). Education and identity (2nd ed.). San Francisco, CA: Jossey Bass.

Child, J., \& Faulkner, D. (1998). Strategies of co-operation: Managing alliances, networks and joint ventures. Oxford: Oxford University Press.

Djerasimovic, S. (2014). Examining the discourses of cross-cultural communication in transnational higher education: From imposition to transformation. Journal of Education for Teaching, 40(3), 204-216.

Dowell, D., Heffernan, T., \& Morrison, M. (2013). Trust formation at the growth stage of a business-to-business relationship. Qualitative Market Research: An International Journal, 6(4), 436-451.

Dwyer, F. R., Schurr, P. H., \& Oh, S. (1987). Developing buyer-seller relationships. Journal of Marketing, 51(2), 11-27.

GATE. (2000). Trade in transnational education services: A report by the global alliance for transnational education. Washington, DC: GATE Publications.

Giddens, A. (1991). Modernity and self-identity. Cambridge: Polity Press.

Gray, B. (1989). Collaborating: Finding common ground for multiparty problems. San Francisco, CA: Jossey Bass.

Gutiérrez, K. D. (2008). Developing a sociocritical literacy in a third space. Reading Research Ouarterlv, 43(2), 148-164.

Hardy, B., Hudson, B., \& Waddington, E. (2000). What makes a good partnership? A partnership assessment tool. Leeds: Nuffield Institute for Health.

Hargreaves, A. (2002). Teaching and betrayal. Teachers and Teaching: Theorv and Practice, $8(3-4), 393-407$.

HEA. (2014a). Framework for partnership in learning and teaching in higher education. York: Higher Education Academy. Retrieved from https://www.heacademy.ac.uk/sites/ default/files/resources/hea_framework_for_partnership_in_learning_and_teaching.pdf

HEA. (2014b). Internationalisation. York: Higher Education Academy. Retrieved from https:// www.heacademy.ac.uk/enhancement/themes/internationalisation

Healey, M., Flint, A., \& Harrington, C. (2014). Engagement through partnership: Students as partners in learning and teaching in higher education. York: Higher Education Academy.

Heffernan, T. (2004). Trust formation in cross-cultural business-to-business relationships. Oualitative Market Research: An International Journal, 7(2), 114-125.

Heffernan, T., \& Poole, D. (2004). "Catch me I'm falling": Key factors in the deterioration of offshore education partnerships. Journal of Higher Education Policv and Management, 26(1), 75-109.

Heffernan, T., \& Poole, D. (2005). In search of 'the vibe': Creating effective international partnerships. Higher Education, 50(2), 223-245.

Hoare, H. (2013). Swimming in the deep end: transnational teaching as culture learning? Higher Education Research \& Development, 32(4), 561-574.

Hodkinson, P., \& Hodkinson, H. (2001). The strengths and limitations of case study research. Paper presented at the Learning and Skills Development Agency Conference 'Making and Impact on Policy and Practice', Cambridge, 5-7 December. 
Hounsell, D., McCune, V., Hounsell, J., \& Litjens, J. (2008). The quality of guidance and feedback to students. Higher Education Research and Development, 27(1), 55-67.

James, D., \& Biesta, G. (2007). Improving learning cultures in further education. Abingdon: Routledge.

Kanter, R. M. (1996). Beyond the cowboy and the corpocrat. In K. Starkey (Ed.), How organisations learn (pp. 43-59). London: International Thomson Business Press.

Keay, J., May, H., \& O' Mahony, J. (2014). Improving learning and teaching in transnational education: Can communities of practice help? Journal of Education for Teaching: International Research and Pedagogy, 40(3), 251-266.

MacFarlane, B. (2009). A leap of faith: The role of trust in higher education teaching. Nagoya Journal of Higher Education, 9(14), 221-238.

Merriam, S. (1998). Qualitative research and case study applications in education. San Francisco, CA: Jossey Bass.

Ministry of Higher Education, Sri Lanka. (2012). National higher education strategic management plan of Sri Lanka: 2012-2015 mid term plan. Retrieved from http://planipolis. iiep.unesco.org/upload/Sri\%20Lanka/Sri_Lanka_National_Higher_Education_Strategic_ Management_Plan_2012-2015.pdf

Montgomery, C. (2014). Transnational and transcultural positionality in globalised higher education. Journal of Education for Teaching, 40(3), 198-203.

Morgan, R., \& Hunt, S. (1994). The commitment - Trust theory of relationship marketing. Journal of Marketing, 58(3), 20-38.

QAA. (2012). UK quality code for higher education, part B: Assuring and enhancing academic quality, chapter B10: Management of collaborative arrangements. Retrieved from http://www. qaa.ac.uk/publications/information-and-guidance/uk-quality-code-for-higher-educationchapter-b10-managing-higher-education-provision-with-others1\#.VdxnJvlVhBc

Rittel, H., \& Webber, M. (1973). Dilemmas in a general theory of planning. Policv Sciences, $4(2), 155-169$.

Rutherford, J. (1990). The third space. Interview with Homi Bhabha. In Ders. (Hg) (Ed.), Identity: Community, culture, difference (pp. 207-221). London: Lawrence and Wishart. Retrieved from http://www.wsp-kultur.uni-bremen.de/summerschool/download\%20ss\%202006/The\%20Third\%20Space.\%20Interview\%20with\%20Homi\%20Bh abha.pdf

Sutton, S. B. (2010). Transforming internationalisation through partnerships. International Educator, 19(1), 60-63.

Sutton, S. B., \& Obst, D. (2011). The changing landscape of international partnerships. In Developing strategic international partnerships: Models for initiating and sustaining innovative institutional linkages. New York: Institute for International Education. Retrieved from https://www.google.co.uk/url?sa $=\mathrm{t} \& \mathrm{rct}=\mathrm{j} \& \mathrm{q}=\&$ esrc $=\mathrm{s} \&$ source $=$ web\&cd $=7 \& \mathrm{cad}=$ rja\&uact $=8 \&$ ved $=0 \mathrm{CEgQFjAG} \& u r l=\mathrm{http} \% 3 \mathrm{~A} \% 2 \mathrm{~F} \% 2 \mathrm{Fwww}$.iie. org $\% 2 \mathrm{~F}^{\sim} \% 2 \mathrm{Fmedia} \% 2 \mathrm{FFiles} \% 2 \mathrm{FC}$ orporate $\% 2 \mathrm{FPublications} \% 2 \mathrm{FPartnership}$-Intro. ashx\&ei $=$ HEPrU4mKCISV7AbD34H4DA\&usg $=$ AFQjCNFhb718QwmUUOAuVMjl ZQfLq4MmtQ\&sig2 = IwMw4brnsrnt-rDtLfeR-A

The Economist Intelligence Unit. (2013). Higher Education in South Asia: Trends in Afghanistan, Bangladesh, India, Nepal, Pakistan and Sri Lanka. A custom research report for the British Council. Retrieved from http://www.britishcouncil.in/sites/britishcouncil. in2/files/sapd_british_council_south_he_report.pdf 
Trahar, S. M. (2013). Autoethnographic journeys in learning and teaching in higher education. European Educational Research Journal, 12(3), 367-375.

Trowler, P. (2012). Wicked issues in situating theory in close-up research. Higher Education Research and Development, 31(3), 273-284.

UK HE International Unit. (2012). International partnerships: A legal guide for UK universities. London: UK HE International Unit. Retrieved from file:///C:/Users/Hazel/Downloads/ Useful $\% 20$ info $\% 20-\% 20$ Eversheds $\% 20$ guide $\% 20$ to $\% 20$ partnerships $\% 202012$.pdf

Wagstaff, D. (2013). What do we know about collaborations and partnership in higher education? London: The Leadership Foundation for Higher Education.

Whitchurch, C. (2008). Shifting identities, blurring boundaries: The changing role of professional managers in higher education. Research and Occasional Paper Series, CSHE.10.2008. Berkeley, CA: Centre for Studies in Higher Education, University of California.

Wildridge, V., Childs, S., Cawthra, L., \& Madget, B. (2004). How to create successful partnerships - A review of the literature. Health Information and Libraries Journal, 21(1), 3-19.

Williams, P. (2010). Special Agents: The nature and role of boundary spanners. Paper to the ESRC Research Seminar Series 'Collaborative Futures: New insights from intra- and inter-sectoral collaborations', University of Birmingham, February 2010.

Williams, P. (2012). Collaboration in public policy and practice: Perspectives on boundary spanners. Bristol: The Policy Press.

World Bank. (2009). Towers of learning: Performance, perils and promise of higher education in Sri Lanka. Retrieved from http://documents.worldbank.org/curated/en/2009/07/ 11137864/towers-learning-performance-peril-promise-higher-education-sri-lanka

Yin, R. K. (2009). Case study research: Design and methods (4th ed.). London: Sage. 